\title{
Experimental and numerical analysis of ceiling panel deflection
}

\author{
Iveta Hegedusova ${ }^{1, *}$, Eva Kormanikova ${ }^{1}$, Kamila Kotrasova $^{1}$ and Sergej Priganc ${ }^{1}$ \\ ${ }^{1}$ Technical University of Kosice, Faculty of Civil Engineering, Institute of Structural Engineering, \\ 04200 Kosice, Slovak Republic
}

\begin{abstract}
The subject matter of the article is the comparison of behaviour of the actual ceiling panels exposed to an aggressive environment and the software-modelled panels while their functioning conditions taken into account are identical. The article presents the comparison based on deflections obtained on the ceiling panels. Comparison is expressed by analysis of the panel load-deflection relation.
\end{abstract}

\section{Introduction}

Agricultural buildings suffer from a long-term exposition to an aggressive environment which has a negative impact on their service life and usability. Aggressive environment parameters, such as humidity, chemical substance concentration, dustiness, etc., largely cause premature degradation of concrete structures. The condition of a structure also depends on the type of building, be it a warehouse or a stable, on the material stored, and on the type of stabled farm animals.

Field research carried out in the past on such buildings in the Slovak Republic resulted in [1], revealing that the buildings are subject to degradation much earlier than expected which is also proved by current inspections [2-5]. Most stable buildings are in especially bad conditions, even in serious disrepair, but despite this fact they are still in use for their purpose [6-8].

The research was aimed at an actual reinforced concrete ceiling structure of a stable building made of precast beams [9]. Inspection on the chosen structure proved multiple faults, such as concrete covering failure, and uncovering and subsequent corrosion of the steel reinforcement, but since no failure was detected in the tension area of reinforcement anchorage, the condition of panels was not declared critical [10]. It was considered to find ways how to reconstruct the ceiling panels in the stable buildings and thus extend their service life [11-12]. The aim of the research was to monitor static characteristics, such as element deflection and crack formation while loading [13].

\footnotetext{
*Corresponding author: iveta.hegedusova@tuke.sk
} 


\section{Description of ceiling panels}

The inspected ceiling panels labelled SZD 10n - 450 are the parts of the reinforced concrete assembled structure K-174 (Fig. 1). The structure K-174 consists from the columns and the beams on which the panels were situated.
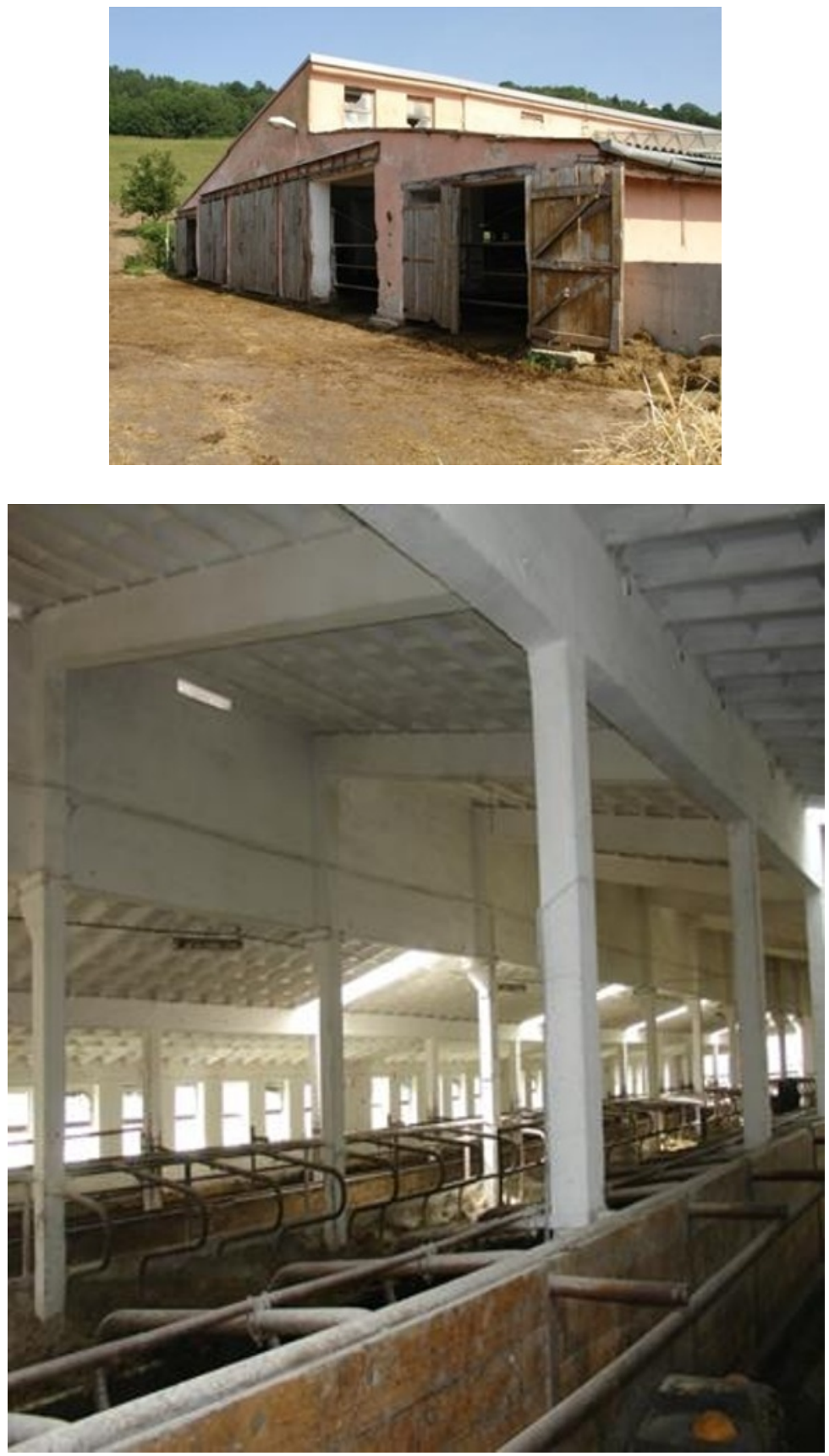

Fig. 1. Object K-174. 
The panel (Fig.2) is the lightened ribbed element with dimension $590 \times 4490 \times 145 \mathrm{~mm}$, while the rib thickness is $30 \mathrm{~mm}$ and the slab thickness is $20 \mathrm{~mm}$. The ribs contain the main load-bearing reinforcement which is created by one rod of diameter $8 \mathrm{~mm}$ and constructional reinforcement with diameter $6 \mathrm{~mm}$. These are extremely lightened load-bearing elements.
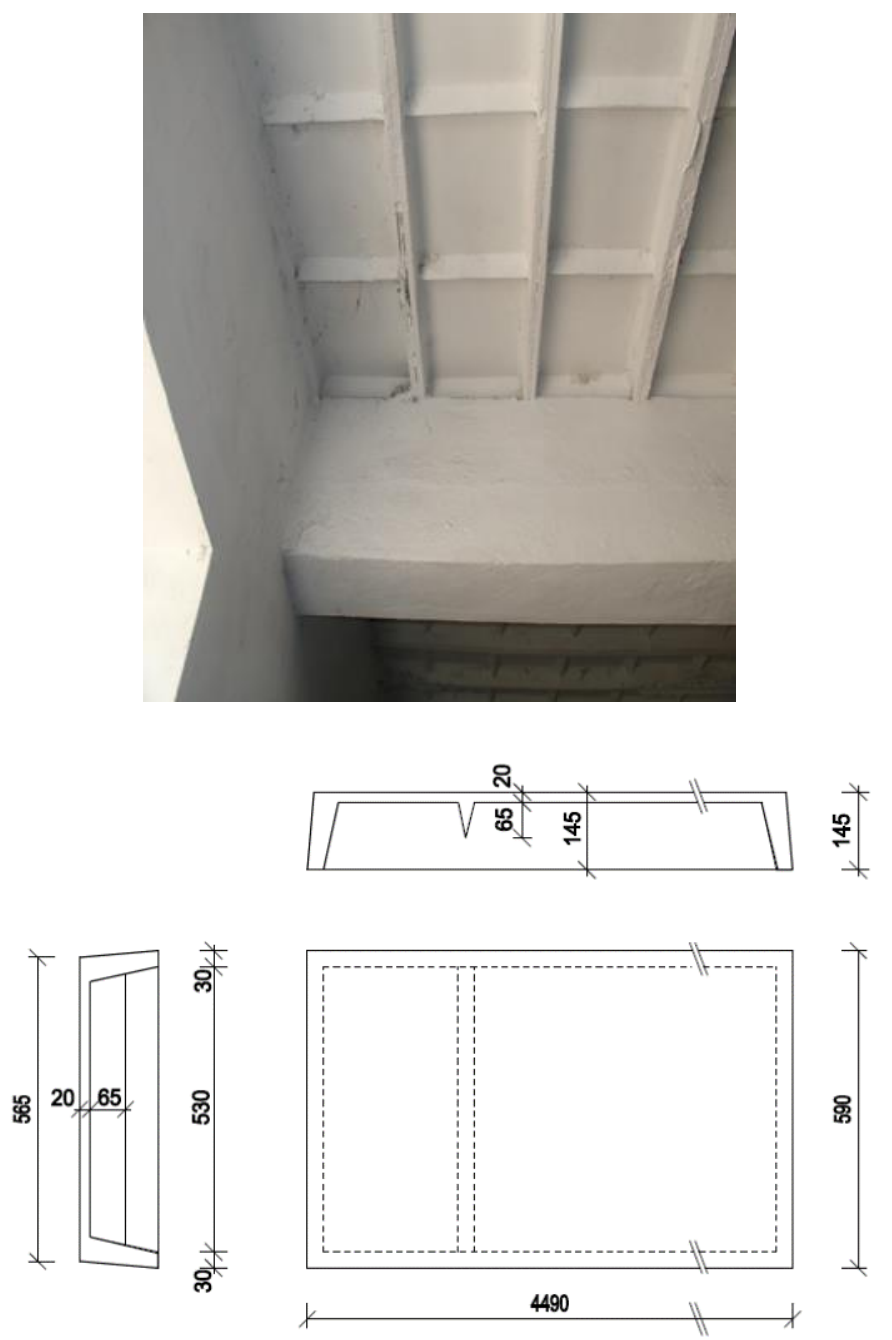

Fig. 2. Ceiling panels.

\section{On-site measurements}

Static measurements carried out in the past on the chosen stable buildings in Liptovský Ondrej, Hrabušice and Koš are described in detail in [1]. The testing method consisted of sample withdrawal - panels from the ceiling structure, the panel preparation for testing (consisting of the visual inspection and recording data to the documentation sheet), and the static test itself. The panels were embedded onto the breaking track and loaded by uniform pneumatic load according to [3]. During loading, in individual specified loading steps, the 
deflection values, the number of cracks and their widths were taken and then recorded in documentation sheets. The set of 31 panels was created.

The actual measured values were later compared with the results of a subsequent parametric analysis.

\section{Parametric analysis}

The aim of the parametric analysis was to model the ceiling panels which would comply with the actual examined panels in substantial parameters based on which their comparison evaluation could be considered sufficient and usable for further statements. The chosen parameters included the panel dimensions, material, i.e. concrete and steel reinforcement, and concrete covering.

The panels were modelled by the program Atena V4 [4] which models by using the finite element method and enables observation of element deformations, such as deflections and cracks.

\subsection{Panel modelling}

The 27 panels were modelled for the experiment (Fig. 3). The Each model was comprised three types of materials: concrete, reinforcement, and steel which was used as a load spreading board at the panel supporting area. Due to symmetry, it was sufficient to model only a half of the panel which decreased the calculation time.

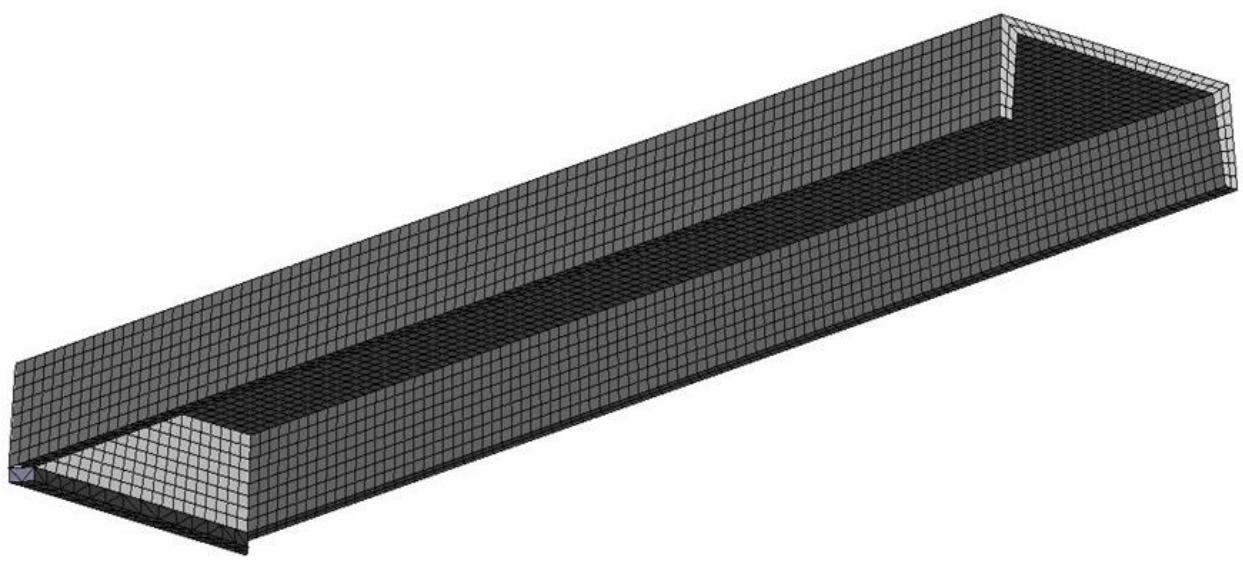

Fig. 3. Model of panel.

In individual models, the chosen input parameters were varied. The three different concrete classes of strength $f_{c k}-21,23,25 \mathrm{MPa}$ were used for concrete, the profiles of 7, 8, $10 \mathrm{~mm}$ diameters were used for reinforcement steel, and the concrete covering values were considered 10, 20, $30 \mathrm{~mm}$. The panels were loaded by increasing compression stress on the top panel surface. The compression stress was considered as a sum of the panel dead weight and the additional load. The resulting parametric simulations present behaviour of the individual panels as load-deflection relations (Fig. 4). 


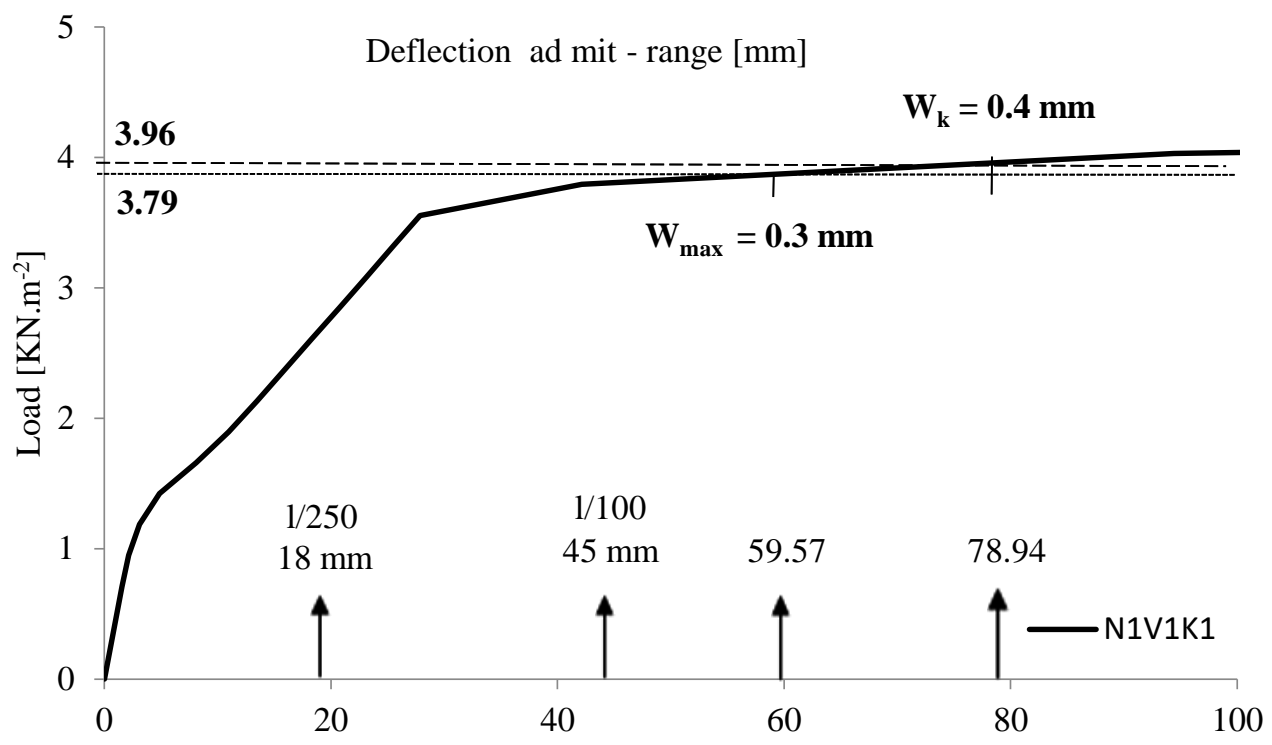

Fig. 4. Stress strain diagram.

\subsection{Analysis}

The numeric analysis was aimed to determine:

- the load values under which the limit deflection values are reached in individual beams,

- the limit crack width was calculated for each beam a deflection value when reaching.

The deflection limit values, and the crack width limit values were considered in accordance with EC [5]. For illustration, values for a beam labelled N1V1K1 are presented (Table 1).

Table 1. Calculated value of load factor.

\begin{tabular}{|c|c|c|c|c|}
\hline \multirow{3}{*}{ Labelling panel } & \multicolumn{4}{|c|}{ Load factor on reaching the limit value $\left[\mathrm{kN} / \mathrm{m}^{-2}\right]$} \\
\cline { 2 - 5 } & $\begin{array}{c}\text { Deflection } \\
l / 100=45 \\
\mathrm{~mm}\end{array}$ & $\begin{array}{c}\text { Deflection } \\
l / 250=18 \\
\mathrm{~mm}\end{array}$ & $\begin{array}{c}\text { Crack } \\
w_{\max }=0.3 \\
\mathrm{~mm}\end{array}$ & $\begin{array}{c}\text { Crack } \\
w_{k}=0.4 \\
\mathrm{~mm}\end{array}$ \\
\hline N1V1K1 & 5.26 & 2.58 & 3.89 & 3.96 \\
\hline
\end{tabular}

The results obtained by the parametric analysis were compared with the ones measured during static tests on actual panels on site. It was created the set of 31 panels for the purpose of comparison, because some faults were detected on individual elements during inspection preceded the static tests. The faults were detected included those arisen during panel production itself and those caused by degradation during the building service life. In multiple panels the designed diameter of concrete reinforcement was not adhered to, and in certain sections of some panels concrete covering was damaged. Thus, only seven out of the whole 
set of 31 panels were usable for the experiment. Those panels were compared with the chosen modelled panels with identical parameters (Table 2). Graphic comparison of panel behaviour is presented in Fig. 5.

Table 2. Comparison panels parameters.

\begin{tabular}{|l|c|c|c|}
\hline \multirow{2}{*}{ Labelling panel } & \multicolumn{3}{|c|}{ Parametes of panel } \\
\cline { 2 - 4 } & Strength [MPa] & $\begin{array}{c}\text { Reinforcement } \\
\text { diameter } \varnothing[\mathrm{mm}]\end{array}$ & Concrete cover [mm] \\
\hline Panel P8 & 25 & 8 & 10 \\
\hline Panel P10 & 25 & 8 & 10 \\
\hline Panel P12 & 25 & 8 & 20 \\
\hline Panel P14 & 25 & 8 & 20 \\
\hline Panel P15 & 25 & 8 & 20 \\
\hline Panel P16 & 25 & 8 & 20 \\
\hline Panel P5 & 25 & 8 & 30 \\
\hline N1V1K1 & 25 & 8 & 20 \\
\hline N1V1K2 & 25 & 8 & 30 \\
\hline N1V1K3 & 25 & 8 & 10 \\
\hline
\end{tabular}

Behaviour comparison of the actual panels and the modelled ones resulted in a decent correspondence. The best correspondence was found in panels labelled N1V1K1 and P5. Deviations as obvious in graphs can be explained by a different degradation degree and a certain inaccuracy during production of actual panels, as well as by a measurement inaccuracy caused by a human factor.

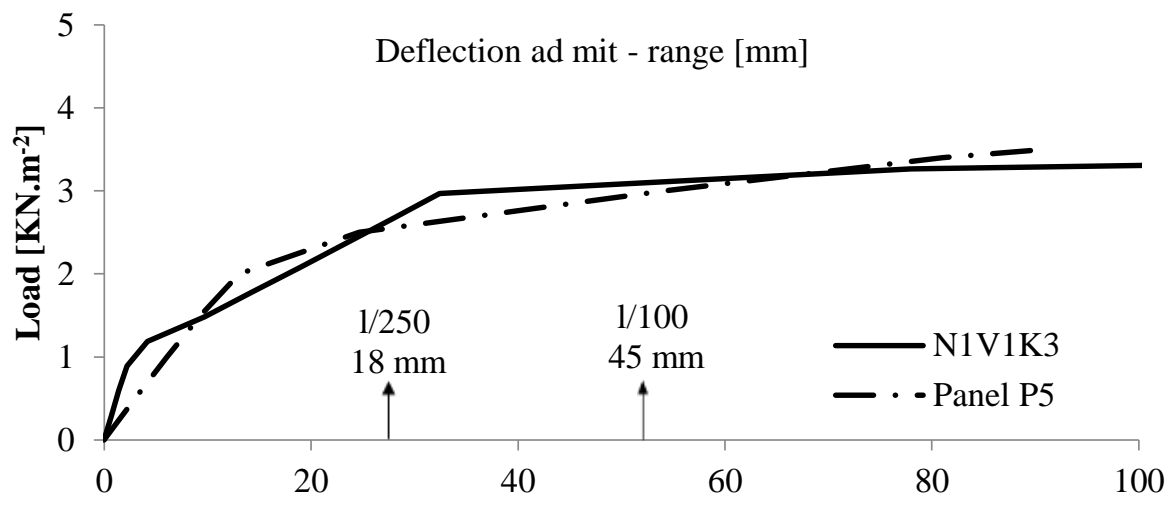

Fig. 5. Stress strain diagram.

\section{Conclusions}

The main aim of the experiment was to find out what correspondence would result from comparison of panels with identical parameters which are built in an actual structure and modelled by a computer program. The comparison resulted in a decent correspondence, i.e. 
identical increasing load caused approximately identical deflection in both sample sets. This correspondence offers a possible use of the ceiling panels modelling method to examine a service life of a structure during a certain period of time based on a load-deflection relation. Comparison of panel behaviour from the crack formation point of view is necessary to be included in the result set as well. Therefore, the presented results will be completed with new findings dealing with examination and comparison of crack formation and their widths measured on actual ceiling panels and the modelled ones.

This work was supported by the Scientific Grant Agency of the Ministry of Education of Slovak Republic and the Slovak Academy of Sciences under Projects VEGA 1/0374/19.

\section{References}

1. L. Fecko, et al., Experimental examination of load-bearing capacity of reinforced concrete ceiling panels in K-174 structure in Liptovský Ondrej and design of alternative treatment to provide required load-bearing capacity. KBaKK, VŠT Košice. Research project R-02-529-811 (1989)

2. I. Hegedüsová, S. Priganc, Analysis of concrete panels properties in an aggressive environment (TU-SvF Košice 2015)

3. L. Fecko, Pneumatic loading of planar elements in static tests. Build. resear. 2 (1983).

4. ATENA Program Documentation Part 8, User's Manual for ATENA GiD Interface (2013). Available at: http://www.cervenka.cz

5. STN EN 1992-1-1. Eurocode 2: Design of concrete structures - Part 1-1 : General rules and rules for buildings (2006)

6. J. P. Broomfield, (Taylor and Francis Group, 2007)

7. P. Schiessl, First Slovak Conference on Concrete Sructures, Slovakia (1994)

8. T. Lo, Proceedings Anual Concrete Seminar. City University of Hong Kong. (2005)

9. O. Sucharda, J. Brožovský, International Journal of Mechanics. 7, 3, 192-200 (2013)

10. M. Krejsa, Z. Kala, S. Seitl, Procedia Engineering, 142, 145-152 (2016)

11. P. Matečková, M. Kozielova, Z. Marcalikova, L. Pazdera, AIP Conference Proceedings, 2113 (2019), article no. 120017

12. Z. Marcalíková, L. Procházka, M. Pesata, V. Bilek, R. Cajka, IOP Conference Series: Materials Science and Engineering, 596, 1 (2019), article no. 012036

13. K. Kotrasová, Kamila, I. Hegedüsová, S. Harabinová, E. Panulinová, E. Kormaníková, Key Engineering Materials, 738, 227-237 (2017) 